\title{
Ancient schwannoma of the median nerve-a case report and review of the literature of nerve tumors
}

\author{
Dr. N. Mariappan \\ (Plastic surgeon, Chennai, India)
}

\begin{abstract}
Schwannomas are known as neurilemmonas, the most common benign tumor of the peripheral nerve's neural sheath, arising from the Schwann cells derived from the neural crest. They are the commonest tumor of the peripheral nerves, $5 \%$ of which occur in the adults. $19 \%$ of the tumors occur in upper extremities and $45 \%$ of schwannoma occur in the head and neck and $13.5 \%$ in the lower limbs. Volar surface is affected more than the dorsal aspect and they may occur as multiple lesions or they may affect different nerves in the same extremity. Despite the classical description that schwannomas are well encapsulated and can be completely enucleated during excision, a portion of them have fascicular involvement and could not be completely shelled out. $75 \%$ of schwannoma of the upper extremity occur at elbow or distal to it. It occurs more in the mixed nerve instead of pure sensory or motor nerve. 50 \%of patients have mixed nerve involvement. An important variant of schwannoma with degenerative changes are termed as Ancient schwannoma. This assumes significance since this may be confused with malignancy in both imaging and in histological studies. A clear understanding is crucial to the treatment plan for nerve tumors. We report a rare case of ancient schwannoma of the median nerve and take a review of the peripheral nerve tumors.
\end{abstract}

Keywords: Ancient schwannoma, malignant peripheral nerve sheath tumors, nerve sheath neoplasm, sural nerve graft, schwannoma/neurilemmonas, peripheral nervous system neoplasm

\section{Introduction}

Schwannoma usually occurs in the age group of 20 to 70 years, It is the tumor of the peripheral nerve's neural sheath, arising from the Schwann cells derived from the neural crest [1] They are present as a painless swelling along the course of the nerves for a long time. They are the commonest tumor of the peripheral nerves, $5 \%$ of which occur in the adults [2]. 19\% of the tumors occur in upper extremities.[3] and 45\% of schwannoma occur in the head and neck and $13.5 \%$ in the lower limbs. Discomfort may be the only complaint of the patient. Paraesthesia may be elicited on tapping of the swelling. The swelling may be misdiagnosed as ganglion, lipoma or lymph node. The tumors are round or ovoid, eccentric and well encapsulated. They are usually $2.5 \mathrm{~cm}$ in size but they may grow up to $4-5 \mathrm{~cm}$. The tumor is grayish, pink, yellow, brown or white in color. They are solitary and found along the anterior aspect of the extremities by the side of the nerves. Ancient schwannomas are a variant of schwannomas of long duration with degenerative changes. In long standing tumors the cut section may show variegated appearance and degenerative changes. The histological and radiological picture resembles that of malignancy but they are benign lesions. This case is reported for the rare nature of the ancient schwannoma of the median nerve and to analyze the surgical options available.

\section{1 case report}

\section{Material and methods}

A 75 years old lady presented with a painless swelling in the right cubital fossa of 10 years duration with complaints of increase in size of the swelling associated with pain for the past one year. She complained of pain and Paraesthesia in the median nerve distribution area of the right hand. She has numbness of the right hand with weakness in performing her day to day activities. There was atrophy of the Thenar muscles. The swelling measured $3.5 \mathrm{~cm}$ in length. The swelling was mobile on the transverse axis and not on the longitudinal axis .There was motor weakness also. Percussion over the nerve produced positive Tinel's sign. There was loss of sensation in the distribution of the median nerve in the hand. The patient refused to undergo MRI examination due to economy reasons. A surgical workup and a pre-operative anesthetist assessment were obtained. With a clinical diagnosis of median nerve tumor the patient was planned for excision of the tumor. It was explained to the patient regarding the neurological deficit following the surgery and she may need a sural nerve graft. Since the patient's functional demand was not high due to her advanced age she refused to have a nerve graft. The patient was taken up for surgery under total intravenous anesthesia with profofol and sulfentanyl with oxygen/air(50\%/50\%) mixture without any neuromuscular blocking agents and tourniquet control. 


\subsection{Procedure}

On exploration the tumor was found to be arising from the median nerve in the right cubital fossa. It was a well encapsulated tumor placed in an eccentric position to the axis of the nerve. The nerve fascicles could not be identified separately. Electro-stimulation showed weak action potentials in the fascicles. The tumor was resected until normal fascicles were identified at both cut ends of the median nerve The proximal and distal cut ends of the nerve were mobilized.

There was a nerve gap of $1.5 \mathrm{~cm}$. after mobilization of both cut ends of the median nerve. It was decided to repair the nerve primarily without sural nerve grafts. The elbow was kept flexed at 90 degrees and the nerve repair was done using 8-0 nylon without tension on the suture line under loupe magnification. The elbow was immobilized in an above elbow pop slab for a period of two weeks after the period of immobilization she underwent a gradual elbow stretching physiotherapy regimen. She was warned about the protection of her right upper extremity and a protective splint was also given. Cut section of the tumor showed degenerative changes with variegated appearance. The specimen was sent for histopathological examination.

\subsection{Surgical principles}

$\mathrm{x}$ Adequate exposure of the nerve both proximal and distal to the tumor $\mathrm{x}$ Perfect hemostasis

$\mathrm{x}$ Loupe or microscopic magnification $\mathrm{x}$ Microsurgical dissection techniques

$\mathrm{x}$ identification of nerve action potential Intraoperatively

$\mathrm{x}_{\text {_ }}$ The vascular pedicle in the proximal part of the tumor is identified first and the remaining tumor can be gently avulsed from the rest of the nerve

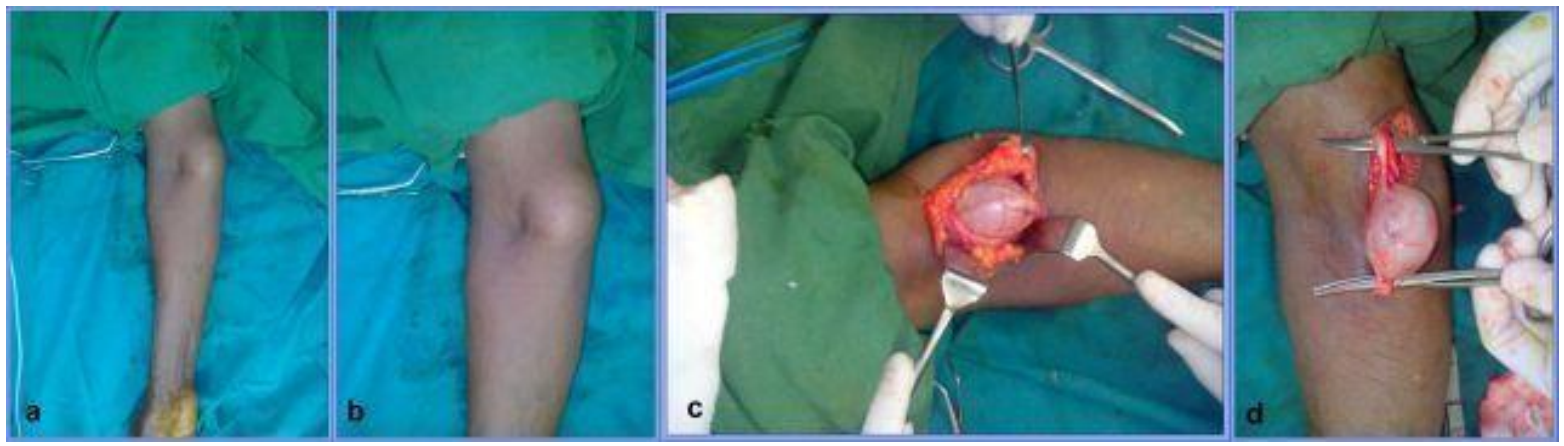

Figure1: Exploration of the tumor arising from the Median nerve.

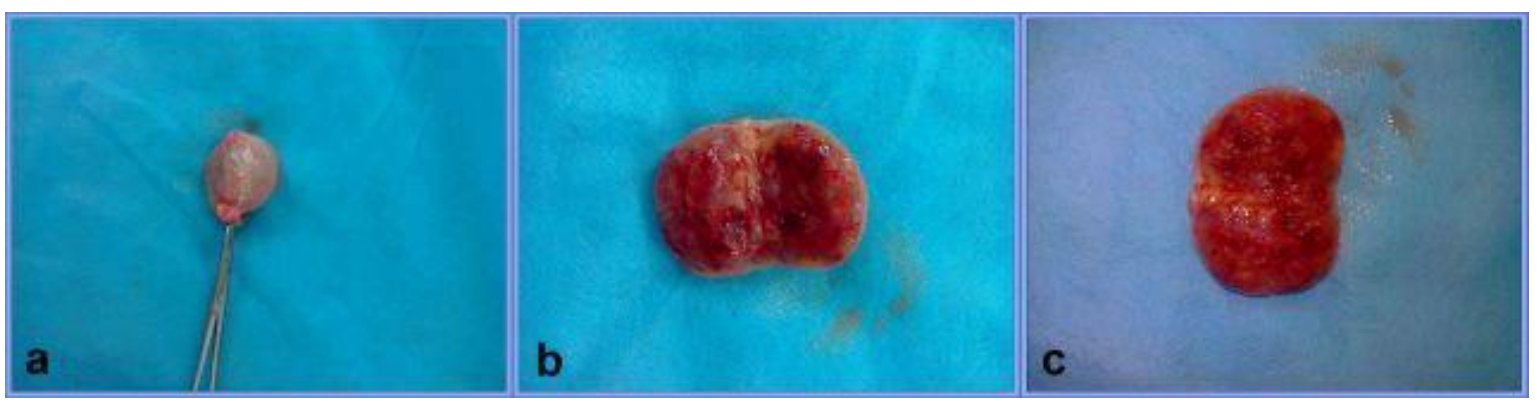

Figure2:The $\mathrm{t} u \mathrm{~m}$ o $\mathrm{r}$ measures $3 \times 3 \times 2 \mathrm{~cm}$ with attached nerves. Cut section appears grayish white with focal myxoid areas.

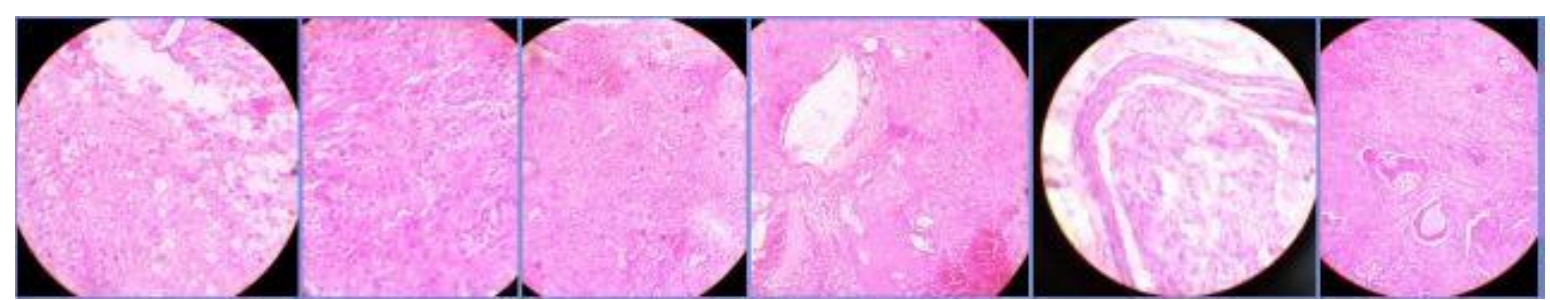

Figure3:Microscopic section of the tumor mass shows foci of Verocey formation and degenerative changes suggestive of ancient schwannoma.

\subsection{Histopathological report}

Histopathological Examination shows an encapsulated neoplasm with a capsule enclosing spindle shaped cells arranged in whorls and fascicles with foci of Verocey formation, cystic changes and myxoid 
degeneration also seen. Impression: median nerve tumor - Schwannoma with cystic changes and myxoid degeneration suggestive of Ancient schwannoma. No evidence of malignancy.

\section{Discussion}

Ancient schwannoma is commonly located deep in the head and neck regions [4,5],Thorax[6] retro peritoneum[7,8],pelvis[9] and extremities [10,11] of elderly patients. Ackerman and Taylor in 1951 described ancient schwannoma with clear areas of hypo cellular tissues due to the long standing degenerative changes attributed to the growth and "aging" of the tumor hence called ancient schwannoma. They identified significant tumor portions contained only a few cells within hyalinised matrices in schwannomas of long duration, hence coined the name "ancient" Review of literature shows most of the ancient schwannoma involve the Head and neck region .A case of ancient schwannoma involving the median nerve at mid humerus level was published by K.Malizos[12]

\subsection{Imaging of Ancient schwannomas}

Very few studies have been done on the radiological features of ancient schwannomas because of the tumor is so rarely encountered. They showed well circumscribed inhomogeneous signal intensity and a different enhancement pattern. Isobe and colleagues reported imaging findings of seven ancient schwannomas mainly in the extremities.[13] The cited author suspected that Antoni type A areas had degenerated to hematomas or cysts. The split fat sign, which is characteristic of benign neurogenic tumor is evident in CT scans. The two MRI features important for differentiating ancient schwannoma from other malignant tumors are that the mass should have a fibrous capsule and the split fat sign should be present.

\subsection{Histology of Ancient Schwannomas}

They are characterized by

$\mathrm{x} \quad$ diffuse hypo cellular areas

$\mathrm{x} \quad$ Relative loss of Antoni type A tissue

$\mathrm{x} \quad$ focal accumulations of hyaline material

$\mathrm{x} \quad$ Calcification

$\mathrm{x} \quad$ cystic necrosis

$\mathrm{x} \quad$ Hemorrhage

x_Fatty necrosis [14] Infiltrated by siderophages and histiocytes and display cellular degenerative changes such as nuclear atypia ,pleomorphism and tendency to nuclear palisading [15] Because of the cystic areas and the histological findings ancient schwannomas are misdiagnosed as malignant tumors.

\section{Peripheral nerve tumors}

Peripheral nerve tumors are uncommon lesions. Multiple specialties are involved in the management Peripheral nerve tumors. Generally they are categorized into nerve sheath, primary neuronal, and non-neuronal neoplasm. Nerve sheath tumors are the most common. Peripheral nerve tumors may be malignant or benign, with the benign tumors more common. The spectrum of peripheral nerve tumors is presented in Table 1.

Table1: Classification of Peripheral Nerve Tumors

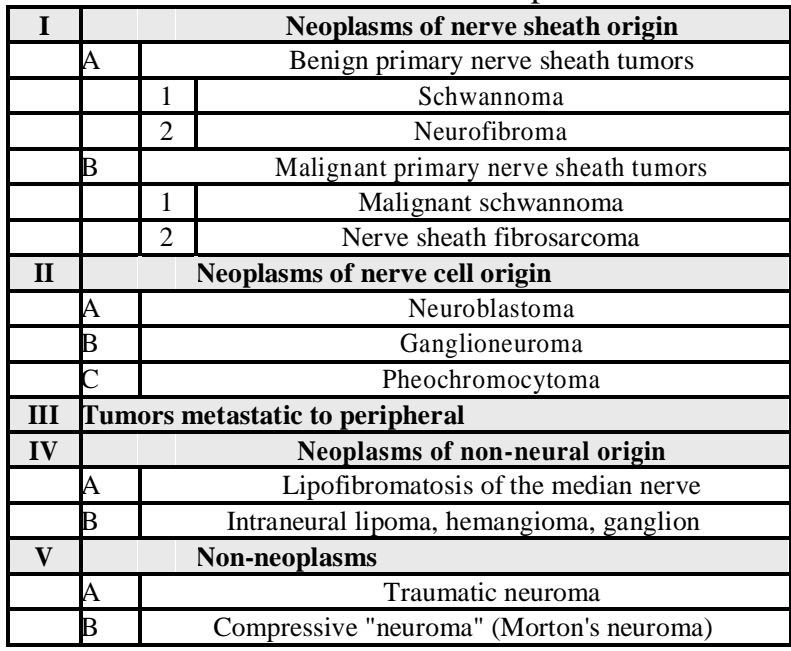




\subsection{Schwannomas}

Schwannomas can arise from any nerve including the peripheral portions of the cranial nerves. These tumors can arise from any nerve covered with a Schwann cell sheath, which include the cranial nerves (except for optic and olfactory), spinal and autonomic nervous system. They are almost solitary. Multiple lesions are rare and may be associated with

$\mathrm{x} \quad$ multiple localized tumors

$\mathrm{x} \quad$ in association with neurofibroma in von Recklinghausen's disease

x_ In schwannomatosis, a non-hereditary disease characterized by multiple subcutaneous and intradermal schwannomas together with tumors of internal organs.

No known etiological factors or no racial or sex predilection is reported. Eighth cranial nerve is the commonly involved. Bilateral eighth cranial nerve schwannomas may be a forme fruste of von Recklinghausen's disease or of neurofibromatosis type 2. Peripherally, schwannomas are most often found in nerves of the head and neck and on the flexor surfaces of the extremities. They rarely occur in the foot. With a solitary lesion without symptoms and without the evidence of neurofibromatosis, there is no need for extensive work up. Excision of the tumor with Biopsy is almost curative. Fascicular involvement was very common in schwannoma ( $75 \%$ of patients). Removal of the tumor with fascicles can cause functional deficit. Interfascicular nerve graft following resection of the nerve along with the tumor gives good result. The nerve graft should be discussed with the patients prior to schwannoma excision, so that nerve grafting could be directly proceeded with patient consent in case there is fascicular involvement of tumor found intraoperatively. Malignant schwannoma constitute $2 \%$ of the nerve sheath tumors and they have a predilection for larger diameter peripheral nerves such as brachial plexus or Sciatic nerve. Malignant transformation of benign schwannomas is unusual [16].The slow growth pattern of the tumor allows for the adaptation of the nerve function to the pressure effects which leads to the delayed presentation and diagnosis[17].Schwannomas of the median nerve are rare tumors.They occur commonly in the distal region of the upper extremity (at elbow or distal), occurs more in the mixed nerves. Two types of presentation are seen.

$\mathrm{x}$ Type 1.Without fascicles involvement and

$\mathrm{x} \quad$ Type.2 With involvement of the fascicles.

In the Type1 without fascicular involvement, the tumor can be completely enucleated without any neurological deficit. In the second Type the neurological deficit depends on the number and the type of fascicles involved. The Patients with schwannomas involving sensory or mixed nerves had positive Tinel's sign. This carries high predictive value ( $87.5 \%$ sensitivity) for schwannomas. Sawada et all demonstrated that schwannomas that could not be enucleated were those located proximal to the middle upper extremity and pre-operatively had sensory disturbances.[18] When motor function loss is expected by intra-operative nerve fascicle stimulation, nerve grafting is recommended. Tumor recurrence is rare even in incomplete resections [19].

\subsection{Imaging of schwannomas}

In MRI, Schwannomas are isotense to muscle in T1-weighted images and hyperintense in T2_weighted ones. [20] Target sign, a sign of entering or exit of the nerve due to low signal intensity centrally (due to central fibrous components )and high signal intensity peripherally (due to peripheral myxomatous elements).Fascicular sign-appearance of fascicular bundles.[21].MRI cannot predict whether the mass can be completely enucleated during the excision.

\subsection{Histology of the Schwannomas 4.3.1 Macroscopic}

x Oval, yellowish

$\mathrm{x} \quad$ Tumor is placed typically eccentric to nerves [22]

$\mathrm{x} \quad$ True capsule

$\mathrm{x}_{-}$Capsule contains perineurium of the nerve bundle of origin surrounded by an onion- like condensation of the deeper layers of the epineurium

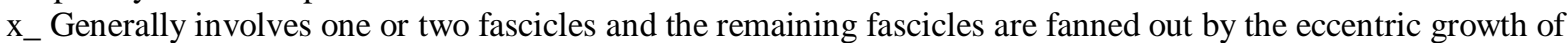
the tumor. 


\subsubsection{Microscopic}

On microscopic examination there are two Variable mixture of Antoni A and B areas are identified

$\mathrm{x}_{\text {_ }}$ Antoni A -Nuclear palisading arrangement. Verocey bodies in which two rows of palisading nuclei are separated by pink fibrillary material(fibrillary, intensely polar, elongated appearing tissue Type A)

x_ Antoni B -Paucicellular, microcystic areas rich in macrophages and collagen fibres.(distinct loose microcystic tissues adjacent to the Antoni A regions)

\subsection{Immunohistochemistry}

The estimation of the following markers are commonly used in the diagnosis

z S100 estimation is commonly done

$\mathrm{Z} \quad$ Vimentin

$\mathrm{z} \quad$ Leu 7

$\mathrm{Z} \quad \mathrm{CD} 34$ is seen only in blood vessels

$\mathrm{Z} \quad \mathrm{Ki} 67$ is positive in $5 \%$ of tumor cells

The following markers used recently are also help in the correct diagnosis of the nerve tumors.

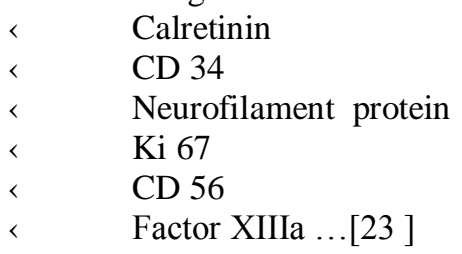

\subsection{Variants of Schwannomas}

Pathobiologic spectrum of schwannomas includes

$\begin{array}{ll}\mathrm{x} & \text { Ancient schwannoma } \\ \mathrm{x} & \text { Cellular schwannoma } \\ \mathrm{x} & \text { Melanotic schwannoma } \\ \mathrm{x} & \text { Neuroblastoma-like schwannoma } \\ \mathrm{x} & \text { Plexiform schwannoma } \\ \mathrm{x} & \text { Epithelioid schwannoma } \\ \mathrm{x} & \text { Glandular schwannoma } \\ \mathrm{x} & \text { Schwannoma-perineurioma. }\end{array}$

\section{Malignant peripheral nerve sheath tumors}

MPNST are sarcomas arising from the peripheral nerves or cells associated with nerve sheath like Schwann cells, perineural cells or fibroblasts. A sarcoma arising from a peripheral nerve or from a neurofibroma is considered to be MPNST. MPNST is a rare disease, with an incidence of 1 in 100000 in the general population [24], with a poor prognosis, with only $20-50 \%$ of the patients surviving 5 years from diagnosis. Sarcoma is defined as MPNST with the following criteria

$\mathrm{x} \quad$ It arises from a peripheral nerve

$\mathrm{x} \quad$ Arises from a pre-existing benign nerve sheath tumor (neurofibroma).

$\mathrm{x} \quad$ Demonstrates Schwann cell differentiation on histologic examination.

World Health Organization has coined the terminology MPNST and this has replaced the old and more confusing terminologies like

$\begin{array}{ll}\text { тм } & \text { Malignant schwannoma } \\ \text { тм } & \text { Malignant neurilemmonas } \\ \text { Tм } & \text { Malignant neuroma } \\ \text { Tм } & \text { Neurofibrosarcoma } \\ \text { Tм } & \text { Neurogenic sarcoma [25] }\end{array}$




\subsection{Epidemiology}

Peripheral nerve sheath tumors are rare. Kransdorf MJ in 1995 reported 77 schwannomas which was only $0.2 \%$ of 39179 soft tissue tumors recorded by the US Armed Forces Institute. The incidence of MPNST in general population is $0.001 \%$ and account for 5 to $10 \%$ of soft tissue sarcomas, about one fourth to one half occurring in the setting of neurofibromatosis.[26]. MPNST are 5-10\% of all soft tissue sarcomas. They arise spontaneously or from pre- existing neurofibromatosis(NF1).The exact etiology is not known but there is higher incidence in patients exposed to radiation.[27,28]

\subsection{IMAGING}

MRI is the imaging modality of choice

$\mathrm{x} \quad$ Fusiform shape and a longitudinal orientation in the direction of the nerve $\mathrm{x}_{-}>5 \mathrm{~cm}$ tumors invasion of fat planes heterogeneity,ill-defined

margins and edema surrounding the lesions around the lesion suggest MPNST.

$\mathrm{x} \quad$ A computed Tomography of the chest

$\mathrm{x} \quad$ Bone scan.

x_ FDG PET , a dynamic modality to evaluate increased metabolic activities seen in malignancies- intracellular glucose use[29].Recently 18FDG PET technology has proved its prognostic relevance.

Table 2:The American Joint Committee on Cancer (AJCC) Staging System for Soft Tissue Sarcoma. MPNST staging.

\begin{tabular}{|c|l|l|l|l|}
\hline Stage & Size & Depth & Grade & Metastases \\
\hline I & Any & Any & Low & No \\
\hline II & Kcm, any depth OR $>5 \mathrm{~cm}$ & Superficial & High & No \\
\hline III & $5 \mathrm{~cm}$ & Deep* & High & No \\
\hline IV & Any & Any & Any & Yes \\
\hline
\end{tabular}

*Depth is termed superficial (above the deep fascia) or deep (deep to the deep fascia). Retroperitoneal tumors are considered deep.

\subsection{Histopathology}

$\mathrm{x} \quad$ Biopsy: FNAC and tru-cut needle biopsy

x_ Histology: $80-85 \%$ is spindle cell tumors with fasciculating pattern similar to fibro-sarcoma. They are high-grade with 4 or more mitotic figures per high power field. Remaining $15 \%$ of MPNST exhibit variable differentiation and they are sub-classified as malignant triton tumor, glandular malignant schwannoma, epithelioid schwannoma and superficial epithelioid MPNST.

S-100 is identified in 50-90\% of MPNST.Leu-7 and myelin basic protein are identified in 50\% and 40\% of the patients.

Treatment includes surgical treatment, radiation therapy and chemotherapy.

\subsection{Prognostic factors of MPNST}

$\mathrm{z} \quad$ Tumor grade

z Large tumor size

$\mathrm{z} \quad$ Deep tumor location

$\mathrm{z} \quad$ Positive surgical margins

z Increased proliferation index of Ki-67 measured by immunohistochemical analysis.score greater than 20 is a significant adverse prognostic Factors.[30].

The treatment modalities for the tumors have been improved with the availability of imaging techniques histology, immunohistochemical studies and development of micro surgery. An algorithm table has been developed by Chris Yuk Kwan Tang et.al. The development of multidisciplinary sarcoma service reviews patient information formulate a treatment plan as decided in sarcoma conference which provides optimal dialogue and an efficient coordination of care. 
Table 3:An algorithm of management of peripheral nerve tumors by Chris Yuk Kwan Tang et al.

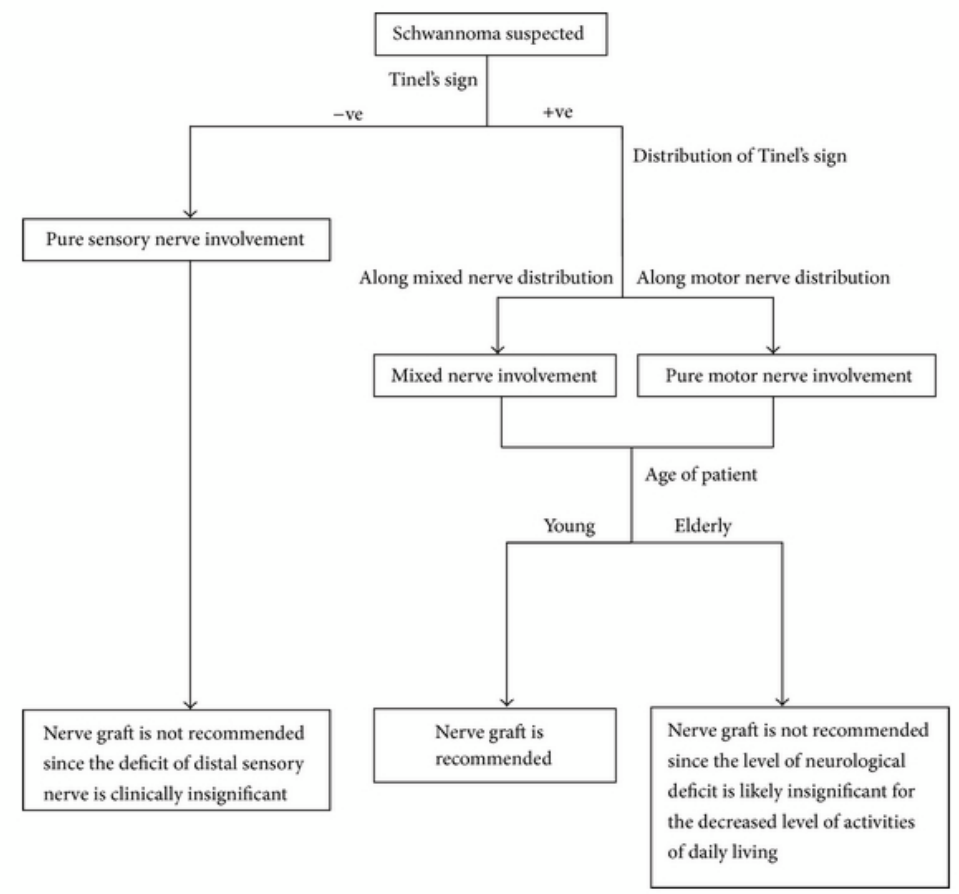

Vl. Conclusion

Ancient schwannoma of the median nerve is a rare benign tumor of the peripheral nerves with degenerative changes of long duration. The diagnosis may be confused with other malignant tumors because of the pleomorphism and nuclei. Investigations like MRI, histology and immuno histochemistry are essential to the correct diagnosis of the tumor. The patients must be informed about the possible neurological deficits and the consent for the possibility of sural nerve grafting must be obtained before surgery. Intra-operative nerve stimulation techniques, frozen section biopsy and preparedness to do sural nerve grafting are important for a successful coordinated treatment of these tumors. The aim of this case report is to review the classification of the peripheral nerves tumor and the treatment algorithm for management of various types of peripheral nerve tumors.

\section{Acknowledgments}

To Dr. Jamila Rose, Pathologist, Chennai for her histopathological review and diagnosis. Her efforts in preparing and sending the slides for this publications is highly appreciated.

\section{Bibiliography}

[1]. Weiss SW, G. J.: Enzinger and Weiss's Soft Tissue Tumors. Edited, St. Louis, Mosby, Inc., 2001.

[2]. C.L.Forthman and P.E.Blazar,'Nerve tumors of the hand and upper extremity,"Hand clinics, vol.20, no.3, pp.233-242, 2004.

[3]. T.K.das Gupta, R.D.Brasfield, E.W.Strong, and S.I.Hsjdu,"Benign solitary schwannomas (neurilemomas)," Cancer,vol.24,no.2,pp.355-366,1969.

[4]. Jayaraj SM, Levine T, Frosh AC, Almeyda JS.Ancient schwannoma masquerading as parotid pleomorphic adenoma. J Laryngol Otol 1997; 111:1088-1090

[5]. Dayan D, Buchner A, Hirschberg A. Ancient neurilemmoma (schwannoma) of the oral cavity. J Craniomaxillofac Surg 1989; 17:280-282

[6]. McCluggage WG, Bharucha H. Primary pulmonary tumours of nerve sheath origin. Histopathology 1995;26:247-254

[7]. Loke TK, Yuen NW, Lo KK, Lo J, Chan JC. Retroperitoneal ancient schwannoma: review of clinico-radiological features. Australas Radiol 1998;42:136-138

[8]. Giglio M, Giasotto V, Medica M, et al. Retroperitoneal ancient schwannoma: case report and analysis of clinico-radiological findings. Ann Urol (Paris) 2002;36:104-106

[9]. Hide IG, Baudouin CJ, Murray SA, Malcolm AJ. Giant ancient schwannoma of the pelvis. Skeletal Radiol 2000;29:538-542

[10]. Graviet S, Sinclair G, Kajani N. Ancient schwannoma of the foot. J Foot Ankle Surg 1995;34:46-50

[11]. Schultz E, Sapan MR, McHeffey-Atkinson B, Naidich JB, Arlen M. Case report 872: "ancient" schwannoma (degenerated neurilemoma). Skeletal Radiol 1994;23:593-595

[12]. Malizos K,Ioannou M,Kontogeorgakos V.Ancient schwannoma involving the median nerve: a case report add review of the literature.Strategies Trauma Limb Reconstr.2013;8:1-4.

[13]. [Isobe K,Shimizu T,Akahane T,Kato H.Imaging of ancient schwannoma.AJR Am J Roentgenol 2004;183:331-6[PubMed

[14]. Eversole LR, Howell RM.Ancient schwannoma of the oral cavity.Oral Surg Oral Med Oral Pathol 1971; 32:440-3[PubMed]

[15]. [Klijjanienko J,Caillaud JM,Lagace R.Cytohistologic correlations in schwannomas (neurilemmomas), including "ancient," cellur, 
and epithelioid variants.Diagn cytopathol 2006; 34:517-22[PubMed].

[16]. [Rekha A, Ravi A.Sciatic nerve schwannoma.Int J Low Extrem Wounds.2004:3:165-167]

[17]. Ogose A,Hotta T, Morita $\mathrm{T}$ et al. Tumors of peripheral nerves: correlation of symptoms, clinical signs,imaging features and histologic diagnosis.Skeletal Radiol.1999;28:183-8.

[18]. Sawada T, Sano M,Ogihara H et all(2006) The relationship between pre-operatives symptoms, operative findings and post-operative complications in schwannomas. J Hand Surg Br 31:629-324.

[19]. Kim DH, Murovic JA, Tiel RL et al(2005) A series of 397 perpheral nerve sheath tumors:30 yearsexperience at Louisiana State University Health Sciences Center.J Neurosurg 102:246-255.

[20]. T.E.J.Hems,P.D.Burge, and D.J.Wilson,"The role of magnetic resonance imaging in the management of peripheral nerve tumors,"journal of Hand surgery,vol.22,no.1,pp.57-60,2009.

[21]. F.D. Beaman, M.J.Kransdorf, and correlation,"Radiographics,vol.24,no,pp.1477-1481,2004.

D.M.Menke, "Schwannoma: radiologic- pathologic

[22]. Vogel KS, K. L., Velasco -Miguel S, Meyers K, Rushing EJ, Parada LF: Mouse tumor model for neurofibromatosis I. Science, 286: 2176-9, 1999

[23]. Hruban RH, S. M., Senie RT, Woodruff JM: Malignant peripheral nerve sheath tumors of the buttock and lower extremity. A study of 43 cases. Cancer, 66((6)): 1253-65, 1990.

[24]. Ducatman BS,Scheithauer BW,Piepgras DG,Reiman HM,Ilstrup DM,Malignant peripheral nerve sheath tumors.A Clinicopathologic study of 120 cases.Cancer.1986;57:2006-2021.

[25]. Gupta G, Maniker A. Malignant peripheral nerve sheath tumors Review. Neurosurg Focus.2007;22(6):E12

[26]. Kransdorf MJ. Benign soft-tissue tumors in a large referral population: distribution ofspecific diagnoses by age, sex, and location. AJR. 1995;164:395-402. 1. Adamson DC,

[27]. C. T., Friedman AH: Malignant peripheral nerve sheath tumor of the spine after radiation therapy for Hodgkin's lymphoma. Clin Neuropathol, 23((5)): 245-55, 2004.

[28]. Amin A, S. A., Flanagan A, Patterson D, Lehovsky J: Radiotherapy-induced malignant peripheral nerve sheath tumor of the cauda equina. Spine, 29((21)): E506-9, 2004

[29]. [Hruban RH,S.M., Senie RT,Woodruff JM: Malignant peripheral nerve sheath tumors of buttock and lower extremity.A study of 43 cases. Cancer,66((6)):1253-65,1990]

[30]. Levine EA,H.T., Baucus S,Mechetner E,Mera R, Bollinger C,Roninson IB,Das Gupta TK:Evaluation of newer prognostic markers for adult soft tissue sarcomas.J Clin Oncol, 15(10):3249-57,!997. 